\title{
Process Consolidation of Al-Cu-Mg Alloy Powders Reinforced with WC Particles
}

G. Rodríguez-Cabriales ${ }^{1}$, A.M. Lometo-Sánchez ${ }^{2}$, I. Estrada-Guel ${ }^{1}$, C.G. Garay-Reyes ${ }^{1}$, M. C. Maldonado-Orozco ${ }^{2}$ and R. Martínez-Sánchez ${ }^{1}$

1. Centro de Investigación en Materiales Avanzados (CIMAV), Laboratorio Nacional de Nanotecnología, Chihuahua, Chih., México.

2. Universidad Autónoma de Chihuahua (UACH), Facultad de Ingeniería, Circuito No. 1, Nuevo Campus Universitario, Chihuahua, Chih., México.

Due to the excellent structural and functional properties, such as low density, high fracture toughness and fatigue strength, $\mathrm{Al}-\mathrm{Cu}-\mathrm{Mg}$ alloy has become an attractive light weight material for inertial instruments and aerospace [1]. Up to date, a wide range of reinforcements have been used to produce Al-based Metal Matrix Composites (MMCs) by Mechanical Alloying (MA) method such as carbides $\left(\mathrm{SiC}, \mathrm{B}_{4} \mathrm{C}, \mathrm{TiC}, \mathrm{Al}_{3} \mathrm{C}_{4}\right)$ nitrides $\left(\mathrm{Si}_{3} \mathrm{~N}_{4}\right)$, borides $\left(\mathrm{TiB}_{2}\right)$ and oxides $\left(\mathrm{SiO}_{2}\right)$. Unfortunately, there is no literature which reports on reinforcing Al matrix using heavier refractory metal powders as reinforcements. Tungsten carbide (WC) is known with its superior hardness, wear and corrosion resistance [2]. Moreover, studies about WC powders like reinforced in Al-based MMCs almost have not been were fabricated by mixing simultaneously elemental powder in the appropriate percentage to obtain chemical composition of $\mathrm{Al}-4 \mathrm{Cu}-1.5 \mathrm{Mg}$ alloy with $1 \mathrm{wt} \%$ of WC. The process of MA was carried out in a high energy mill (Spex-8000) during 3 and $5 \mathrm{~h}$ of milling time ( $\mathrm{mt}$ ) in an argon atmosphere. The milling device and milling media used in the experiments were made from hardened steel. The milling ball-to-powder ratio was 5 to 1, methanol was added as process control agent. The alloy powders were cold compacted at $1868 \mathrm{MPa}$. The samples obtained were sintered at temperatures of 450, 500 and $550^{\circ} \mathrm{C}$, during $3 \mathrm{~h}$ under argon atmosphere. The microstructural characterization was realized by scanning electron microscopy and structural characterization was determined by X-ray diffraction. A SEM Hitachi model SU3500 and PANalytical X'Pert PRO diffractometer was used for different characterizations. The mechanical performance of the samples was evaluated by Vickers microhardness in a LM300AT tester, 10 indentations in every sample were realized. Finally, the density was measured by Archimedes' method.

The Fig. 1, shows SEM micrographs obtained from Al-Cu-Mg-WC samples. It is appreciated that at higher $\mathrm{mt}$ the sample is more porous due to greater deformation hardening caused by MA, making it more difficult the consolidation process. Besides, it is presents the Al-Cu phase formation. The Fig. 2, shows a) and b) graphs of density and Vickers microhardness as a function of milling time and sintered temperature, c) XRD diffractograms obtained after $3 \mathrm{~h}$ of milling and different sintered temperature. It is concluded that at $3 \mathrm{~h}$ milling time and $450{ }^{\circ} \mathrm{C}$ of sintered temperature, the Al-Cu-Mg-WC composite shows the best mechanical behavior.

References:

[1] Y. F. Song et al, J Alloys Compd 701 (2017), p. 508.

[2] Alper Evirgen, M. Lütfi Öveçoğlu, J Alloys Compd 496 (2010), p. 212. 

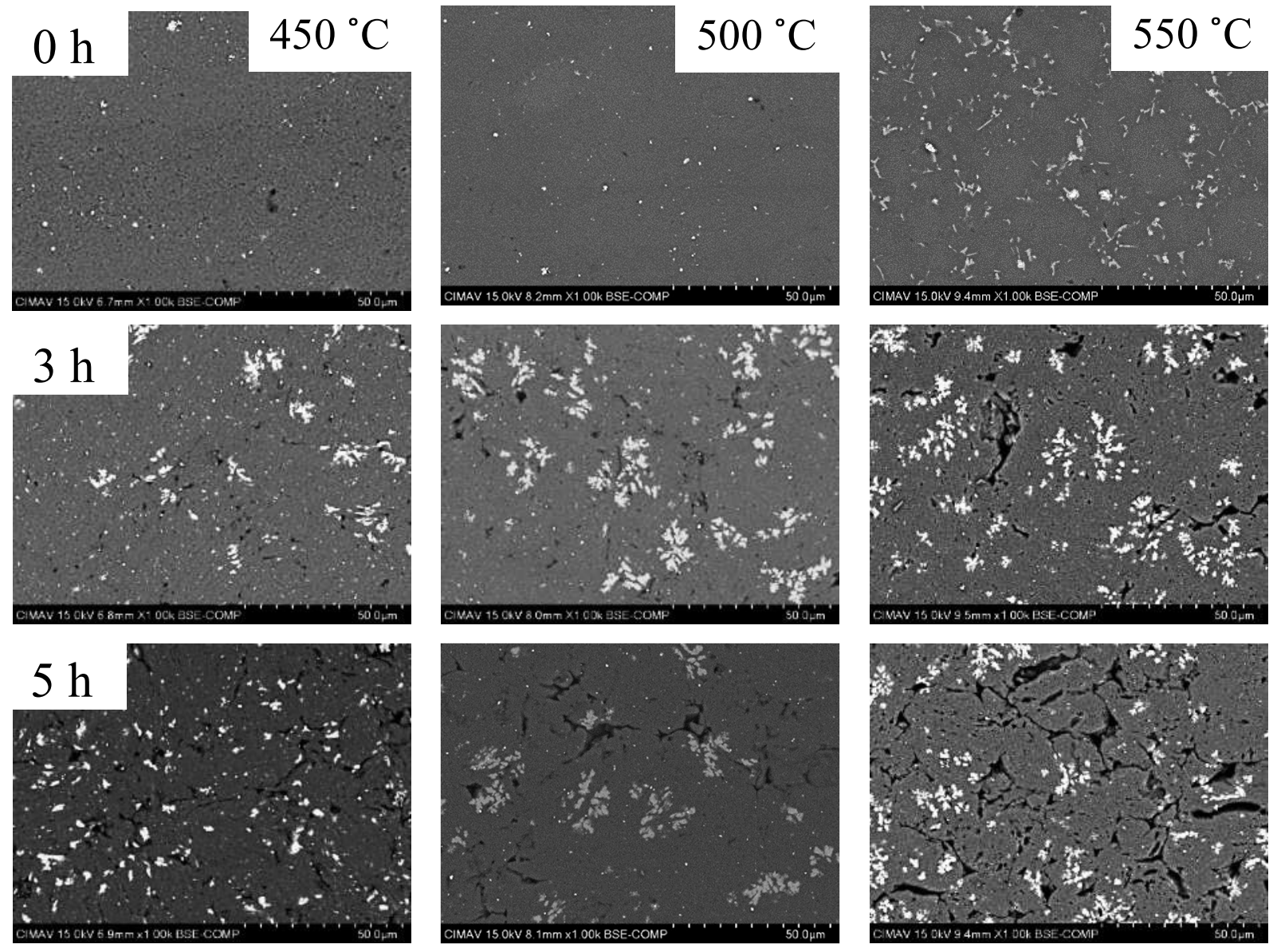

Figure 1. SEM micrographs obtained from Al-Cu-Mg-WC samples from up to down 0,3 and $5 \mathrm{~h}$ of $\mathrm{mt}$ and from left to right 450,500 and $550{ }^{\circ} \mathrm{C}$ of sintered temperature.
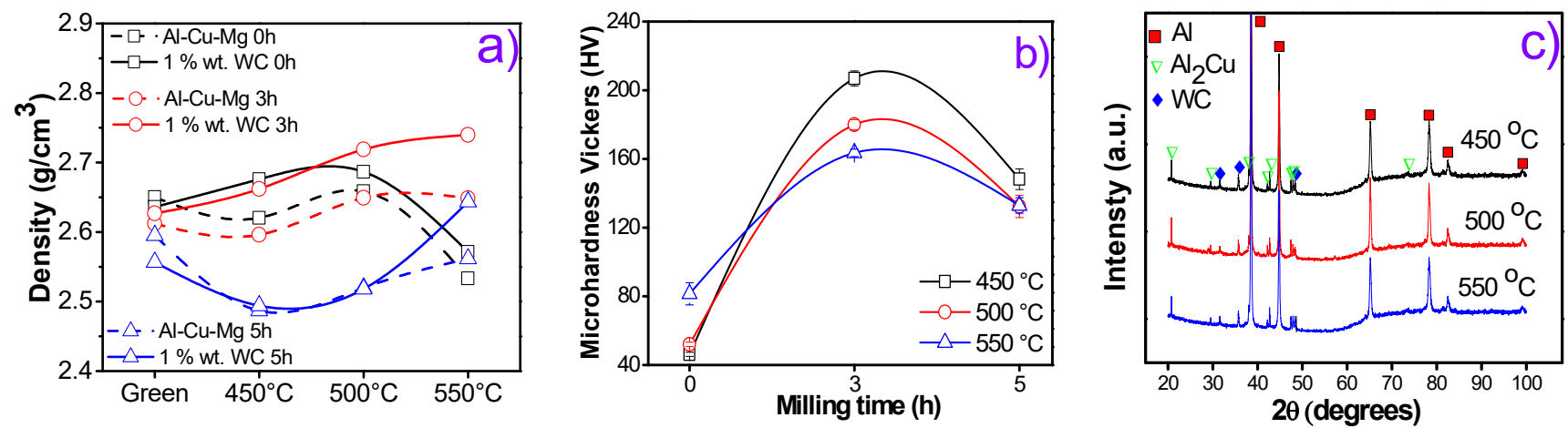

Figure 2. a) Density values of $\mathrm{Al}-\mathrm{Cu}-\mathrm{Mg}-\mathrm{WC}$ and $\mathrm{Al}-\mathrm{Cu}-\mathrm{Mg}$ samples after 0,3 and $5 \mathrm{~h}$ of milling, b) Vickers microhardnes values of Al-Cu-Mg-WC samples in function of sintered temperature and mt and c) XRD diffractograms obtained from $\mathrm{Al}-\mathrm{Cu}-\mathrm{Mg}-\mathrm{WC}$ samples after $3 \mathrm{~h}$ of milling and different sintered temperature. 